\title{
Erratum to: Detection of a novel circovirus PCV3 in pigs with cardiac and multi-systemic inflammation
}

Tung Gia Phan 1,2, Federico Giannitti ${ }^{3,4}$, Stephanie Rossow ${ }^{3}$, Douglas Marthaler ${ }^{3}$, Todd P. Knutson ${ }^{3}$, Linlin Li ${ }^{1,2}$, Xutao Deng ${ }^{1}$, Talita Resende ${ }^{3}$, Fabio Vannucci ${ }^{3}$ and Eric Delwart ${ }^{1,2^{*}}$

\section{Erratum}

Following publication of this article [1], it has come to our attention that the middle initial on the author, "Todd Knutson", should not have been omitted as it is part of his professional title, Todd P. Knutson. The original version of this article was revised.

\footnotetext{
Author details

'Blood Systems Research Institute, San Francisco, CA 94118, USA.

${ }^{2}$ Department of Laboratory Medicine, University of California at San Francisco, San Francisco, CA 94118, USA. ${ }^{3}$ Veterinary Diagnostic Laboratory, University of Minnesota, Saint Paul, MN 55108, USA. Instituto Nacional de Investigación Agropecuaria, La Estanzuela, Colonia 70000, Uruguay.
}

Received: 20 April 2017 Accepted: 21 April 2017

Published online: 28 April 2017

\section{Reference}

1. Phan T, Giannitti F, Rossow S, Marthaler D, Knutson T, Li L, et al. Detection

of a novel circovirus PCV3 in pigs with cardiac and multi-systemic

inflammation. Virol J. 2016;13:1. doi:10.1186/s12985-016-0642-z.

\footnotetext{
* Correspondence: delwarte@medicine.ucsf.edu

${ }^{1}$ Blood Systems Research Institute, San Francisco, CA 94118, USA

${ }^{2}$ Department of Laboratory Medicine, University of California at San

Francisco, San Francisco, CA 94118, USA

Full list of author information is available at the end of the article
} 